Original Article

\title{
Comparison of basic physical fitness, aerobic capacity, and isokinetic strength between national and international level high school freestyle swimmers
}

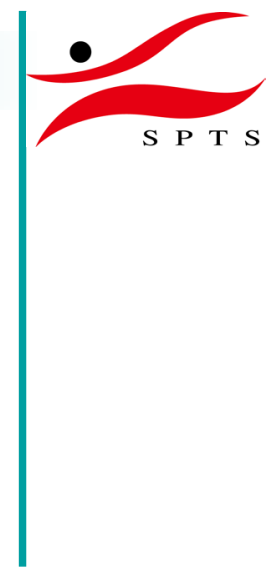

\author{
Young-Hyeon Bae, PT, PhD ${ }^{1,2)}$, Jae-Ho Yu, PT, PhD ${ }^{3)}$, Suk Min Lee, PT, PhD ${ }^{4}$ * \\ 1) Department of Physical Medicine and Rehabilitation, Samsung Medical Center, Republic of Korea \\ 2) Department of Physical Therapy (DPT program), Angelo State University, USA \\ 3) Department of Physical Therapy, Sunmoon University, Republic of Korea \\ 4) Department of Physical Therapy, Sahmyook University: 26-21 Gongneung 2 -dong, Nowon-gu, Seoul \\ 01795, Republic of Korea
}

\begin{abstract}
Purpose] This study aimed to compare basic physical fitness, aerobic capacity, and isokinetic strength between international and national level freestyle high school student swimmers. [Subjects and Methods] A total of 28 participants (14 international level swimmers and 14 national level freestyle high school student swimmers) with no known pathology were included. We used a cross-sectional study to examine three variables: basic physical fitness, aerobic capacity, and isokinetic strength. [Results] The mean values of these variables in the international level swimmers were higher than those in the national level swimmers. Swimmers are generally physically fit with a good competition record. [Conclusion] An appropriate training program, which considers specific individual characteristics is likely to have a positive impact on the improvement of total physical fitness, and subsequently, on the performance of the freestyle high school swimmer.

Key words: Aerobic capacity, Muscle strength, Swimmer
\end{abstract}

(This article was submitted Nov. 18, 2015, and was accepted Dec. 11, 2015)

\section{INTRODUCTION}

Swimming requires muscle strength, as the arms perform the power to swing by water. Master level swimmers might use the overhead shoulder joint position up to 11,000 or more times in one week of training ${ }^{1}$. Swimming requires the repetitive nature of movements that can frequently lead to soft tissue micro-trauma in the shoulder joint ${ }^{2,3)}$. In addition, imbalance of muscle strength and flexibility loss has been implicated in shoulder joint injuries ${ }^{4}$; a major reason for the loss of time in training ${ }^{5)}$. Other reports recognize that swimmers experience many back problems ${ }^{6,7)}$. There is little information on the role of trunk strength in swimming. As one's arms swing in the water, the trunk provides a stable platform for the arm and leg motions, as evidenced by high electromyographic (EMG) muscle activity recorded in the back and abdominal muscles during swimming ${ }^{8)}$. There is insufficient information regarding muscle strength and swimmer levels.

Previous studies have described the body composition and anthropometric characteristics in young swimmers ${ }^{9-11)}$. These studies demonstrate the association between physical functions and the difference in swimming performance levels, the status of training experience, and age ${ }^{9-11)}$. Swimmers of a young age have high muscle strength and aerobic capacity than non-swimmers of a comparable age. In additional, swimmers of a young age had properly weight of Body and fat-free mass and percent of body fat than older swimmers ${ }^{9-11)}$. There are no reports on the aerobic capacity of swimmers according to swimming levels.

\footnotetext{
*Corresponding author. Suk Min Lee (E-mail: leesm@syu.ac.kr)

(C)2016 The Society of Physical Therapy Science. Published by IPEC Inc.

This is an open-access article distributed under the terms of the Creative Commons Attribution Non-Commercial No Derivatives (by-nc-nd) License $<$ http://creativecommons.org/licenses/by-nc-nd/4.0/>.
} 
The relationship between basic physical fitness, isokinetic strength, and aerobic capacity in swimmers remains imprecise $^{12,13)}$. Therefore, the purpose of this study was to compare basic physical fitness, aerobic capacity, and isokinetic strength between international and national level freestyle high school swimmers.

\section{SUBJECTS AND METHODS}

We included a total of 28 participants (14 international level swimmers and 14 national level freestyle high school swimmers) with no known pathology in the study. We excluded those who were on any medication or likely to take any medication during the study period. All participants gave informed consent according to the method outlined by the institutional review board before study participation. This study was cross-sectional in nature and examined three variables.

All participants underwent an evaluation of basic physical fitness, isokinetic strength, and aerobic capacity. Following the evaluation, these three variables were compared between the international level swimmers and national level swimmers.

Body composition was analyzed using a portable eight-polar tactile-electrode impedancio-meter (InBody 3.0, Biospace, Gateshead, UK). This device was used to measure height $(\mathrm{cm})$, weight $(\mathrm{kg})$, fat mass $(\%)$, skeletal muscle mass $(\mathrm{kg})$, and body mass index (BMI) $\left(\mathrm{kg} / \mathrm{m}^{2}\right)$. We performed the measurements under the following conditions: at least two hours after the last meal, without clothes on, without any metallic objects on the body, and after remaining in a standing position for a minimum of five minutes before the test.

Evaluation of physical fitness was performed using Helmas 2.0 (O2 Run, Inc., Seoul, Korea). The isometric test in this evaluation tested the strength of the back muscles. Concerning muscular endurance, the number of sit-ups performed in 30 seconds was assessed. For testing agility, a standing high jump was performed twice; we recorded the higher score. Trunk flexibility was tested with the sit and reach movement performed twice, during which we assessed the range of the forward movement of the trunk.

Peak torques in the shoulder, lumbar, and knee joints were measured to assess isokinetic muscle strength using the HUMAC $^{\circledR} /$ NORM Cybex (CSMI) 770 dynamometer. We repeated the isokinetic strength test three times; we recorded the peak torque as the participant's strength. We adopted low angular velocities $\left(60^{\circ}\right.$ /second) to measure concentric isokinetic strength ${ }^{14,15)}$.

The sub-maximal graded exercise treadmill test consisted of a real-time recording 12-channel electrocardiography (Q5000, Quinton Instrument Co., Boston, MA, USA), a respiratory gas analyzer (QMC, Quinton Instrument Co.), an automatic blood pressure and pulse monitor (Model 412, Quinton Instrument Co.), and a treadmill (Medtrack ST 55, Quinton Instrument Co.) for evaluating aerobic capacity. The investigator evaluated the exercise heart rate (HR) and rating of perceived exertion (RPE) score at the end of each stage. We assessed the maximal oxygen uptake $\left(\mathrm{VO}_{2} \mathrm{max}\right)$ through a respiratory gas analyzer $\left.{ }^{16}\right)$.

The results are shown using descriptive statistics: mean and standard deviation (SD). For variables with a normal distribution, the independent t-test was used for comparison between the two groups. Data analysis was performed using SPSS version 21 (SPSS Inc., Chicago, IL, USA). In all cases, the level of significance was set at $\mathrm{p}<0.05$.

\section{RESULTS}

The mean age, weight, height, BMI, fat-free mass, body fat mass, body muscle mass, and body fat \% distribution of the international level swimmers and national level swimmers were not significantly different (Table 1).

The mean values of the strength of the back muscles, sit-ups, standing high jumps, and sit and reach movement in the international level swimmers were significantly higher than those in the national level swimmers $(\mathrm{p}<0.05)($ Table 2$)$.

The international level swimmers scored higher on the peak torque in the shoulder joint, lumbar spine, and knee joint than the national level swimmers; there was a significant difference in trunk extension, knee extension, and internal and external shoulder rotation between the groups $(\mathrm{p}<0.05)$ (Table 3$)$.

The mean values of the $\mathrm{VO}_{2} \max , \mathrm{VO}_{2} \max \%$, and body weight in the international level swimmers were significantly higher than those in the national level swimmers $(\mathrm{p}<0.05)$ (Table 4$)$.

\section{DISCUSSION}

Swimming involves complicated, coordinated, high muscle fiber contractions, with $40-200$ or more repetitions ${ }^{17)}$. The positive relationship between muscle strength, $\mathrm{VO}_{2} \mathrm{max}$, and stroke length are important observations made in previous studies. Muscle strength and $\mathrm{VO}_{2}$ max are considered important features of a successful swimming performance ${ }^{18-23)}$. Therefore, the purpose of this study was to compare basic physical fitness, aerobic capacity, and isokinetic strength between international level swimmers and national level swimmers.

Swimmers usually focus on improving performance by optimizing their swimming technique rather than increasing their muscle strength ${ }^{21,24,25)}$. In our study, the mean values of basic physical fitness and isokinetic strength in the international level swimmers were higher than those in the national level swimmers. The associations among basic physical fitness, muscle strength, and performance become more evident at high swimming velocities, specifically in shorter duration competitions $^{21,24,25)}$. McMaster et al. showed an increase in strength of shoulder rotators in swimmers compared with that in 
Table 1. General characteristics and body composition of the participants

\begin{tabular}{lrc}
\hline \multirow{2}{*}{ Variable } & International swimmers & National swimmers \\
\cline { 2 - 3 } & Mean $\pm \mathrm{SD}$ & Mean $\pm \mathrm{SD}$ \\
\hline Age (years) & $16.8 \pm 0.8$ & $17.4 \pm 0.8$ \\
Height $(\mathrm{cm})$ & $177.4 \pm 3.7$ & $175.5 \pm 3.1$ \\
Weight $(\mathrm{kg})$ & $73.7 \pm 6.4$ & $69.9 \pm 3.2$ \\
BMI $\left(\mathrm{kg} / \mathrm{m}^{2}\right)$ & $23.4 \pm 1.3$ & $22.7 \pm 0.7$ \\
BFM $(\mathrm{kg})$ & $10.7 \pm 1.9$ & $10.3 \pm 0.8$ \\
LBM $(\mathrm{kg})$ & $63.0 \pm 4.8$ & $60.7 \pm 3.3$ \\
Muscle mass $(\mathrm{kg})$ & $59.4 \pm 4.5$ & $57.2 \pm 3.2$ \\
BFP $(\%)$ & $13.4 \pm 1.7$ & $13.3 \pm 1.3$ \\
\hline
\end{tabular}

No significant difference between both the groups. BMI: body mass index, BFM: body fat mass, LBM: lean body mass, BFP: body fat percentage

Table 2. General characteristics and body composition of the participants

\begin{tabular}{lcc}
\hline \multirow{2}{*}{ Variable } & International swimmers & National swimmers \\
\cline { 2 - 3 } & Mean $\pm \mathrm{SD}$ & Mean $\pm \mathrm{SD}$ \\
\hline Back muscle strength $(\mathrm{kg})$ & $150.0 \pm 9.5$ & $139.1 \pm 8.1^{*}$ \\
Sit-up (frequency) & $30.4 \pm 3.6$ & $27.0 \pm 2.6^{*}$ \\
Standing high jump $(\mathrm{cm})$ & $58.3 \pm 7.7$ & $52.6 \pm 6.9^{*}$ \\
Sit \& reach $(\mathrm{cm})$ & $21.6 \pm 4.2$ & $18.1 \pm 4.0^{*}$ \\
\hline
\end{tabular}

$* \mathrm{p}<0.05$, significantly difference between both the groups

Table 3. Comparison of isokinetic strength of trunk, knee, and shoulder between both the groups

\begin{tabular}{|c|c|c|c|c|c|}
\hline \multirow{2}{*}{ Variable } & & & & International swimmers & National swimmers \\
\hline & & & & Mean \pm SD & Mean \pm SD \\
\hline \multirow{10}{*}{$\begin{array}{l}\text { Peak torque } \\
\text { (ft-lbs) }\end{array}$} & \multirow{2}{*}{ Trunk } & \multirow{2}{*}{\multicolumn{2}{|c|}{$\begin{array}{l}\text { Flexion } \\
\text { Extension }\end{array}$}} & $137.2 \pm 13.3$ & $127.0 \pm 11.8$ \\
\hline & & & & $147.3 \pm 14.1$ & $135.5 \pm 12.5^{*}$ \\
\hline & \multirow{4}{*}{ Knee } & \multirow{2}{*}{ Right } & Flexion & $97.3 \pm 10.5$ & $91.0 \pm 9.3$ \\
\hline & & & Extension & $146.5 \pm 16.0$ & $132.5 \pm 15.2^{*}$ \\
\hline & & \multirow{2}{*}{ Left } & Flexion & $95.1 \pm 8.2$ & $87.4 \pm 9.4$ \\
\hline & & & Extension & $142.6 \pm 16.2$ & $130.4 \pm 14.6^{*}$ \\
\hline & \multirow{4}{*}{ Shoulder } & \multirow{2}{*}{ Right } & Internal Rotation & $110.2 \pm 12.4$ & $98.7 \pm 10.1^{*}$ \\
\hline & & & External Rotation & $78.6 \pm 9.3$ & $70.0 \pm 8.2^{*}$ \\
\hline & & \multirow{2}{*}{ Left } & Internal Rotation & $103.9 \pm 10.3$ & $93.2 \pm 8.3^{*}$ \\
\hline & & & External Rotation & $74.7 \pm 9.8$ & $65.0 \pm 8.0^{*}$ \\
\hline
\end{tabular}

$* \mathrm{p}<0.05$, significantly difference between the both groups

Table 4. Comparison of aerobic capacity between both the groups

\begin{tabular}{lcc}
\hline \multirow{2}{*}{ Variable } & International swimmers & National swimmers \\
\cline { 2 - 3 } & Mean $\pm \mathrm{SD}$ & Mean $\pm \mathrm{SD}$ \\
\hline $\mathrm{VO}_{2} \mathrm{max}(\mathrm{ml} / \mathrm{min})$ & $4,244.0 \pm 591.0$ & $3,722.1 \pm 587.1^{*}$ \\
$\mathrm{VO}_{2} \mathrm{max} \%$ Body weight $(\mathrm{ml} / \mathrm{min} / \mathrm{kg})$ & $57.6 \pm 5.8$ & $53.2 \pm 4.9^{*}$ \\
\hline
\end{tabular}

$\mathrm{VO}_{2}$ max: Maximal oxygen uptake, ${ }^{*} \mathrm{p}<0.05$, significantly difference between both the groups

non-swimmers ${ }^{5)}$. Additionally, the trunk position controls an important role in supplying a stable platform from which the low and upper extremities can conduct powerful motions ${ }^{10)}$. EMG data confirms that the rectus abdominis is one of the muscles most accountable for propulsion through swimming ${ }^{10}$. Moreover, EMG activity in the back and abdominal muscles 
is higher in competitive swimmers than in non-competitive swimmers during freestyle swimming ${ }^{10)}$.

The international level swimmers scored higher than the national level swimmers on the peak torque in $\mathrm{VO}_{2}$ max and $\mathrm{VO}_{2} \max \%$ body weight in our study. $\mathrm{VO}_{2}$ max in absolute and relative terms was significantly higher in the trained group compared to the untrained group. We expected this as swimming is an aerobic exercise that greatly taxes the oxygen transport system. This kind of training augments $\mathrm{VO}_{2} \mathrm{max}$ and, therefore, improves physical fitness ${ }^{16,26}$ ) $\mathrm{VO}_{2}$ max values were $31.5 \%$ higher, and the relative values were approximately $20 \%$ higher in the trained group compared to the untrained group; this was considered significant in previous studies ${ }^{16,26)}$.

In conclusion, freestyle swimmers are generally physically fit and seem to have a good competition record. Therefore, there is a need to consistently evaluate the physical performance of freestyle swimmers using a variety of assessment devices. In addition to this, an appropriate training program, which considers specific individual characteristics, is likely to have a positive impact on the improvement of physical fitness, and subsequently, on the performance of the freestyle swimmers.

\section{ACKNOWLEDGEMENT}

This study was supported by Sahmyook University.

\section{REFERENCES}

1) Wanivenhaus F, Fox AJ, Chaudhury S, et al.: Epidemiology of injuries and prevention strategies in competitive swimmers. Sports Health, 2012, 4: 246-251. [Medline] [CrossRef]

2) Ciullo JV, Stevens GG: The prevention and treatment of injuries to the shoulder in swimming. Sports Med, 1989, 7 : 182-204. [Medline] [CrossRef]

3) Perry J: Anatomy and biomechanics of the shoulder in throwing, swimming, gymnastics, and tennis. Clin Sports Med, 1983, 2: 247-270. [Medline]

4) Warner JJ, Micheli LJ, Arslanian LE, et al.: Patterns of flexibility, laxity, and strength in normal shoulders and shoulders with instability and impingement. Am J Sports Med, 1990, 18: 366-375. [Medline] [CrossRef]

5) McMaster WC, Troup J: A survey of interfering shoulder pain in United States competitive swimmers. Am J Sports Med, 1993, 21: 67-70. [Medline] [CrossRef]

6) Bak K: [Injuries in swimmers. Locomotor system injuries in competitive swimmers]. Ugeskr Laeger, 1990, 152: 22202224. [Medline]

7) Goldstein JD, Berger PE, Windler GE, et al.: Spine injuries in gymnasts and swimmers. An epidemiologic investigation. Am J Sports Med, 1991, 19: 463-468. [Medline] [CrossRef]

8) Lauer J, Figueiredo P, Vilas-Boas JP, et al.: Phase-dependence of elbow muscle coactivation in front crawl swimming. J Electromyogr Kinesiol, 2013, 23: 820-825. [Medline] [CrossRef]

9) Geladas ND, Nassis GP, Pavlicevic S: Somatic and physical traits affecting sprint swimming performance in young swimmers. Int J Sports Med, 2005, 26: 139-144. [Medline] [CrossRef]

10) Jürimäe J, Haljaste K, Cicchella A, et al.: Analysis of swimming performance from physical, physiological, and biomechanical parameters in young swimmers. Pediatr Exerc Sci, 2007, 19: 70-81. [Medline]

11) Richardson J, Beerman $K$, Heiss $C$, et al.: Comparison of body weight and body fat classifications of competitive school-age club swimmers. J Am Diet Assoc, 2000, 100: 237-240. [Medline] [CrossRef]

12) Olbrecht J, Madsen $O$, Mader A, et al.: Relationship between swimming velocity and lactic concentration during continuous and intermittent training exercises. Int J Sports Med, 1985, 6: 74-77. [Medline] [CrossRef]

13) Sharp RL, Troup JP, Costill DL: Relationship between power and sprint freestyle swimming. Med Sci Sports Exerc, 1982, 14: 53-56. [Medline] [CrossRef]

14) Noh JW, Park BS, Kim MY, et al.: Analysis of isokinetic muscle strength for sports physiotherapy research in Korean ssireum athletes. J Phys Ther Sci, 2015, 27: 3223-3226. [Medline] [CrossRef]

15) Lin HT, Ko HT, Lee KC, et al.: The changes in shoulder rotation strength ratio for various shoulder positions and speeds in the scapular plane between baseball players and non-players. J Phys Ther Sci, 2015, 27: 1559-1563. [Medline] [CrossRef]

16) Mercier J, Vago P, Ramonatxo M, et al.: Effect of aerobic training quantity on the VO2 max of circumpubertal swimmers. Int J Sports Med, 1987, 8: 26-30. [Medline] [CrossRef] 
17) Morouço P, Keskinen KL, Vilas-Boas JP, et al.: Relationship between tethered forces and the four swimming techniques performance. J Appl Biomech, 2011, 27: 161-169. [Medline]

18) Cardelli C, Lerda R, Chollet D: Analysis of breathing in the crawl as a function of skill and stroke characteristics. Percept Mot Skills, 2000, 90: 979-987. [Medline] [CrossRef]

19) Chatard JC, Collomp C, Maglischo E, et al.: Swimming skill and stroking characteristics of front crawl swimmers. Int J Sports Med, 1990, 11: 156-161. [Medline] [CrossRef]

20) Chengalur SN, Brown PL: An analysis of male and female Olympic swimmers in the 200-meter events. Can J Sport Sci, 1992, 17: 104-109. [Medline]

21) Costill DL, Kovaleski J, Porter D, et al.: Energy expenditure during front crawl swimming: predicting success in middle-distance events. Int J Sports Med, 1985, 6: 266-270. [Medline] [CrossRef]

22) Craig AB Jr, Skehan PL, Pawelczyk JA, et al.: Velocity, stroke rate, and distance per stroke during elite swimming competition. Med Sci Sports Exerc, 1985, 17: 625-634. [Medline] [CrossRef]

23) Francaux M, Ramyead R, Sturbois X: Physical fitness of young Belgian swimmers. J Sports Med Phys Fitness, 1987, 27: 197-204. [Medline]

24) Toussaint HM, Vervoorn K: Effects of specific high resistance training in the water on competitive swimmers. Int $\mathrm{J}$ Sports Med, 1990, 11: 228-233. [Medline] [CrossRef]

25) Hawley JA, Williams MM, Vickovic MM, et al.: Muscle power predicts freestyle swimming performance. Br J Sports Med, 1992, 26: 151-155. [Medline] [CrossRef]

26) Ribeiro JP, Cadavid E, Baena J, et al.: Metabolic predictors of middle-distance swimming performance. Br J Sports Med, 1990, 24: 196-200. [Medline] [CrossRef] 